\title{
The effect of location and post-treatment on the microstructure of EBM-built Alloy 718
}

Sneha Goel $^{\mathrm{a}}$, Jonas Olsson ${ }^{\mathrm{a}}$, Magnus Ahlfors ${ }^{\mathrm{b}}$, Uta Klement ${ }^{\mathrm{c}}$, Shrikant Joshi ${ }^{\mathrm{a}}$

aDepartment of Engineering Science, University West, S-461 86 Trollhättan, Sweden

buintus Technologies AB, S-721 66 Västerås, Sweden

'Department of Industrial and Materials Science, Chalmers University of Technology, S-412 96 Gothenburg, Sweden

\section{Contact details of all the authors:}

Sneha Goel: sneha.goel@hv.se, Tel: +46(0)520223298

Jonas Olsson: jonas.olsson@ @v.se, Tel: +46(0)520223492

Magnus Ahlfors: magnus.ahlfors@ quintusteam.com, Tel: +46(0)21-32 7000

Uta Klement: uta.klement@chalmers.se, Tel: +46(0)31-772 1264

Shrikant Joshi: shrikant.joshi@hv.se, Tel: +46(0)520223336

\begin{abstract}
Additive manufacturing (AM) of Ni-based superalloys such as Alloy 718 may obviate the need for difficult machining and welding operations associated with geometrically intricate parts, thus potentially expanding design possibilities and facilitating cost-effective manufacture of complex components. However, processing AM builds completely free from defects, which may impair mechanical properties such as fatigue and ductility, is challenging. Anisotropic properties, microstructural heterogeneities and local formation of undesired phases are additional concerns that have motivated post-treatment of AM builds. This work investigates the microstructural changes associated with post-treatment of Alloy 718 specimens produced by Electron Beam Melting (EBM) for as-built microstructures at 3 build heights: near base plate, in the middle of build and near the top of the build. Two different post-treatment conditions, hot isostatic pressing (HIP) alone and a combined HIP with solutionising and two-step aging were examined and compared to the results for the as-built condition. The influence of various posttreatments on minor phase distributions ( $\delta, \gamma$ ", carbides), overall porosity, longitudinal grain widths and Vickers microhardness was considered. The HIP treatment led to significant reduction in overall porosity and dissolution of $\delta$ phase, which led to appreciable grain growth for both post-treatment conditions. The variation in hardness
\end{abstract}


noted as a function of build height for the as-built specimens was eliminated after post-treatment. Overall, the hardness was found to decrease after HIP and increase after the full HIP, solutionising and aging treatment, which was attributed to dissolution of $\gamma$ " during HIP and its re-precipitation in subsequent heat treatment steps.

\section{Keywords}

Additive manufacturing, Electron beam melting, Alloy 718, HIP, Heat treatment, Microstructure, XRD, Hardness, $\delta, \gamma "$ Carbide

\section{Introduction}

Alloy 718, usually referred to as Inconel 718, is a Ni-Fe based superalloy widely used in the aerospace industry by virtue of the excellent balance of mechanical properties and corrosion resistance that it affords at high temperature [1]. While Alloy 718 parts have been traditionally fabricated using conventional cast and wrought $(\mathrm{C} \& \mathrm{~W})$ techniques, there has been a growing interest in production of the complex high temperature service components through additive manufacturing (AM) processes due to the significant design freedom offered by the technology. Alloy 718 has been processed by laser (laser metal deposition, LMD; selective laser melting, SLM) and electron (Electron Beam Melting, EBM) beam based technologies [2]-[4]. AM, in general, involves high solidification rates and high thermal gradients, thus resulting in a finer microstructure compared to C\&W products [5]. In EBM, a relatively high temperature is maintained throughout the process compared to SLM, thus resulting in lower residual stresses in as-manufactured parts [6]. However, as a relatively newer technology, the degree to which the EBM processing conditions (scanning strategies, preheat and melting parameters) affect the properties of EBM-built Alloy 718 material is less understood compared to the laser based techniques. Also, it has been challenging to date to build Alloy 718 parts that are free from issues such as defects, inhomogeneity, anisotropy, etc., thereby demanding post-treatment to achieve the required microstructure and intended part performance. Although post treatment of C\&W Alloy 718 has been widely investigated over several decades [7]-[9], the inadequacy of conventional post-treatment protocols for EBM Alloy 718 [10]-[12], justifies further investigation of microstructural changes that occur in EBM-built Alloy 718 during post-treatment. A comprehensive study may eventually allow optimization of the combined build and post-treatment processes to obtain components with properties deployable in severe environments. 
Entrapped gas porosity and interdendritic shrinkage porosity is often observed in EBM-built Alloy 718 [11], [13] and has been one of the drivers for subjecting EBM builds to a hot isostatic pressing (HIP) post-treatment in an effort to improve mechanical properties. The strength exhibited by Alloy 718 is known to be derived from the precipitation of the fine $\gamma^{\prime \prime}$ and $\gamma^{\prime}$ phases and solid solution strengthening of the FCC $\gamma$ matrix (Ni solid solution) [14]. On prolonged exposure at temperatures higher than $650^{\circ} \mathrm{C}$, the major strengthening $\gamma^{\prime}$ phase (metastable) may transform into the equilibrium $\delta$ phase, thus resulting in loss of strength [8]. At higher temperature (900$1000^{\circ} \mathrm{C}$ ), the latter is known to precipitate directly from the matrix [15]. Other precipitates commonly found in Alloy 718 also include carbides and nitrides. Previously published work on post-treatment of EBM-built Alloy 718 involved HIP for healing the defects by plastic flow, solution treatment (ST) to dissolve the secondary phases such as the $\delta$ phase, and aging to precipitate the desired strengthening phases like $\gamma$ " [10]-[12]. Kirka et al. have reported significant improvement in low cycle fatigue behaviour of EBM built Alloy 718 after post-treatment in comparison to the as-built material [16], presumably as a consequence of the above.

In the present study, EBM-built Alloy 718 specimens with build architecture related variations in microstructural features were subjected to two different post-treatments - one involving only HIP and the other including HIP and heat treatment (solution treatment and aging) carried out in the same cycle within the HIP vessel. A comprehensive investigation of the as-built and post-treated specimens was carried out using optical microscopy, scanning electron microscopy, energy dispersive spectroscopy and X-ray diffraction technique. The changes in microhardness accompanying the post-treatments were also evaluated and correlated to the secondary phases present.

\section{Experimental}

\subsection{EBM building of Alloy 718 specimens}

The starting powder was plasma wire atomized Alloy 718 supplied by Advanced Powders and Coatings (Quebec, Canada). The particle size distribution of the powder was $45-105 \mu \mathrm{m}$ and its nominal chemical composition is shown in Fig. 1 Schematic of (a) the entire EBM build and (b) specimens \#1, \#2, \#3 were analysed for this investigation.

Table 1. An Arcam A2X EBM machine equipped with EBM Control V4.2.2O1 was used for additively building a series of specimens $(50 \times 50 \times 7 \mathrm{~mm})$, which were loaded as a group along with the other geometries as shown in Fig. 1(a). For the present study, the specimens marked \#1,\#2 and \#3 (and henceforth referred thus in the text) in Fig. 1(b) were analysed after fabrication and after post-treatments to study the microstructural variations at different locations in the overall build architecture of $5 \mathrm{~mm}, 61 \mathrm{~mm}$ and $117 \mathrm{~mm}$ in $\mathrm{Z}$ build heights, respectively. 
The support structures between specimens (marked in black in the schematic shown in Fig. 1) are built to improve the heat energy dissipation from the specimen. The process parameters employed were the standard settings recommended by Arcam and the build process was initiated after the stainless steel base plate was pre-heated to $1025^{\circ} \mathrm{C}$. The acceleration voltage and layer thickness were set to $60 \mathrm{kV}$ and $75 \mu \mathrm{m}$, respectively. With the advance of each layer, the scan direction was rotated by $\sim 72^{\circ}$.
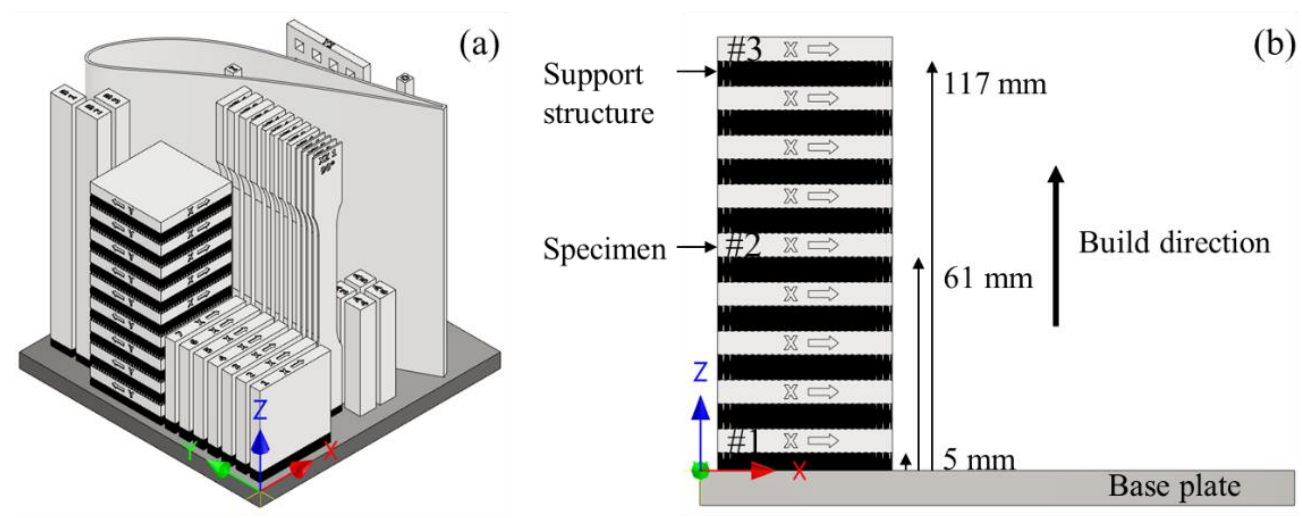

Fig. 1 Schematic of (a) the entire EBM build and (b) specimens \#1, \#2, \#3 were analysed for this investigation.

Table 1 Nominal chemical composition (wt.\%) of the Alloy 718 powder used.

\begin{tabular}{llllllllll}
\hline Element & Ni & Cr & Fe & Nb+Ta & Mo & Ti & Cu & Al & C \\
\hline Powder Alloy 718 & 54.11 & 19.0 & $\sim 12.2$ & 4.97 & 2.99 & 1.02 & 0.0 & 0.52 & 0.03 \\
\hline
\end{tabular}

\subsection{Post-treatment}

Two different post-treatments, HIP and HIP+HT, were carried out on all the three as-built EBM Alloy 718 specimens at Quintus Technologies $\mathrm{AB}$ as per details listed in Table 2. For post-compaction, a hot isostatic press (Model QIH21, Quintus Technologies, Västerås, Sweden) with a molybdenum furnace capable of a maximum temperature of $1450{ }^{\circ} \mathrm{C}$ and a maximum gas pressure of $207 \mathrm{MPa}$ was used. Argon 4.6 was utilised as the inert process gas. Before starting the HIP process, the pressure chamber was evacuated, flooded with argon, and then evacuated again. After this procedure, the pressure and temperature were increased simultaneously to tier respective set points. When both values were stable, the holding time was started. The post-treatment labelled 'HIP+HT' involved combined HIP, solution treatment and aging being carried out as a single cycle inside the HIP vessel. The process graphs of the two post-treatments are shown in Fig. 2(a) and (b). As may be seen from these graphs, the specimens were rapidly cooled to room temperature in the HIP vessel in case of both the posttreatments. 
Table 2 Designation of post-treatments and their corresponding details.

\begin{tabular}{ll}
\hline Post-treatment & Cycle \\
\hline HIP & $1200{ }^{\circ} \mathrm{C} / 120 \mathrm{MPa} / 4 \mathrm{~h} / \mathrm{RC}$ \\
\hline HIP+HT & $1185^{\circ} \mathrm{C} / 170 \mathrm{MPa} / 3 \mathrm{~h} / \mathrm{FC}$ (approx. $\left.25^{\circ} \mathrm{C} / \mathrm{min}\right)$ to \\
& Solution treatment: $980{ }^{\circ} \mathrm{C} / 1 \mathrm{~h} / \mathrm{RC}$ to RT \\
& Aging: $740^{\circ} \mathrm{C} / 8 \mathrm{~h} / \mathrm{FC}$ to $635^{\circ} \mathrm{C} / 10 \mathrm{~h} / \mathrm{RC}$ to $\mathrm{RT}$
\end{tabular}

Note: FC, RC, and RT denote furnace cooling, rapid cooling, and room temperature, respectively.
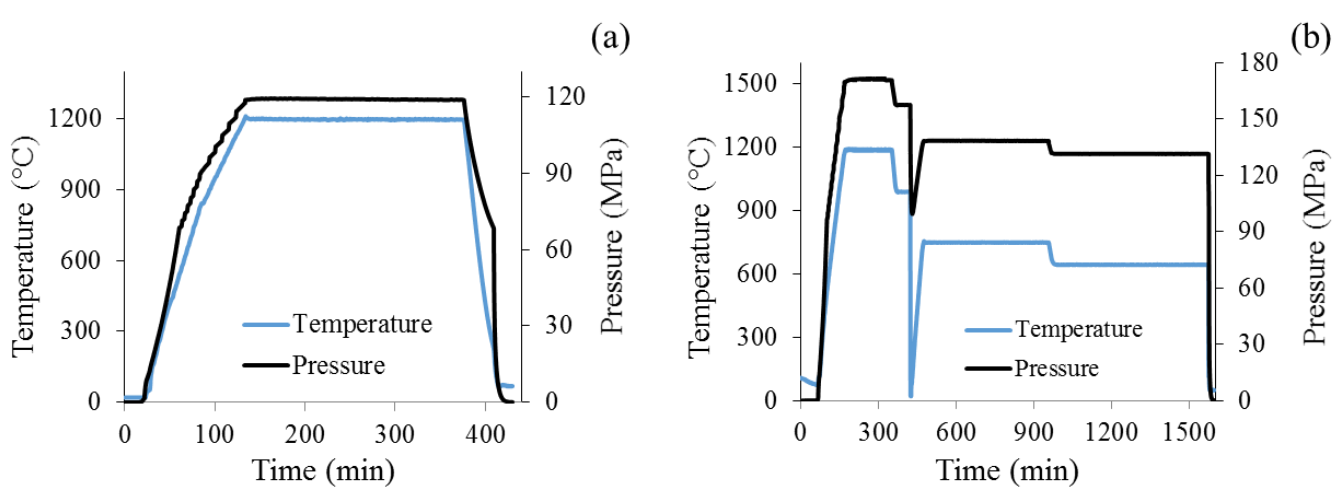

Fig. 2 Process graph showing temperature and pressure variation with time during (a) HIP and (b) HIP+HT treatment.

\subsection{Characterization}

For microstructure analysis, all the specimens were sectioned using an alumina cutting blade, and the transverse sections, i.e., sections along the build direction, were hot mounted. The mounted specimens were semiautomatically polished using a Buehler PowerPro 5000 (Buehler, USA) system. The polished specimens were etched via electrolytic (2-4 V) etching using oxalic acid, and submersion etching using $\mathrm{HCl}-\mathrm{HNO}_{3}-\mathrm{CH}_{3} \mathrm{COOH}$ (1:1:1) and Kalling's reagent to reveal the microstructure and then examined under an Optical Microscope (OM) (Olympus BX60M, HOFSTRAgroup®, US) and a Scanning Electron Microscope (SEM) (HITACHI TM3000, Zeiss EVO 50 and LEO 1550 Gemini equipped with a field emission gun) investigation. Image analysis was employed for quantification of porosity (using ASTM E1245-03 automatic image analysis method [17] and the open source ImageJ software) using 15 images and carbide content (using ASTM E562-11 manual point count method [18]) using 8-10 images. An Energy Dispersive Spectroscopy (EDS) (Oxford instruments, UK) detector 
mounted on the Zeiss EVO 50 SEM was applied for elemental analysis. Longitudinal grain width measurements were done using SEM micrographs, employing line intercept method [3], [19]. A Bruker D8 equipment was used to conduct X-Ray Diffraction (XRD) analysis utilising $\mathrm{Cr} \mathrm{K}_{\alpha}$ radiation, with a step size and scan rate of $0.1 \mathrm{deg} / \mathrm{step}$ and $2.0 \mathrm{~s}$ step, respectively. Vickers micro-hardness testing (HMV-2, Shimadzu Corp., Japan) on the polished cross-sections was performed using 500g load applied for $15 \mathrm{~s}$ in ambient conditions. Ten to fifteen hardness indents were recorded for each specimen tested.

\section{Results and discussion}

\subsection{Microstructure of as-built specimens}

One of the features of primary interest in as-built EBM Alloy 718 structures is the presence of defects. Three different types of defects that are commonly observed (a) shrinkage porosity, (b) gas porosity and (c) lack-offusion are shown in Fig. 3 for the EBM-built Alloy 718 specimens evaluated in the present study. The shrinkage porosity is usually aligned along the build direction and has been reported to result from interdendritic shrinkage [12], while the gas porosity appears circular in two-dimensions and has been attributed to the entrapped gas in the starting powder. The lack-of-fusion is irregular in shape and is a consequence of incomplete fusion between the layers [20].
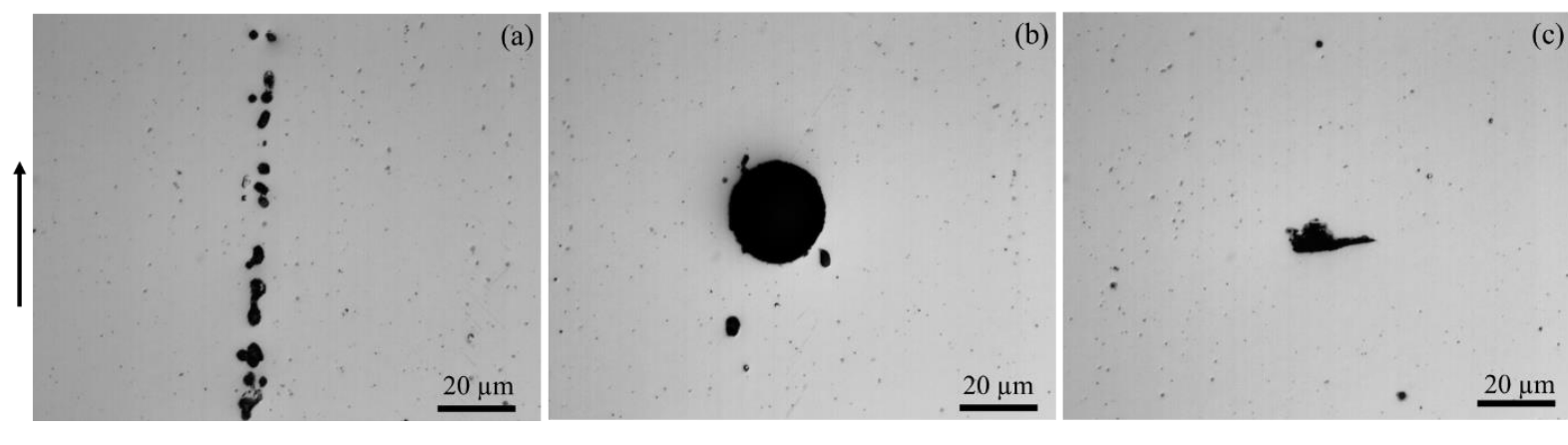

Fig. 3 OM micrographs showing different kinds of defects in the EBM as-built Alloy 718: (a) shrinkage porosity, (b) gas porosity and (c) lack-of-fusion. The arrow indicates the build direction.

The low magnification microstructures of the as-built specimens \#1, \#2 and \#3 are shown in Fig. 4. The epitaxial growth of columnar grains along the build direction can be clearly seen and the majority of grains grow across several layers (layer thickness: $75 \mu \mathrm{m}$ ) in the build direction. Due to the strong longitudinal orientation of the grains, longitudinal grain width rather than the grain diameter was measured. Fig. 4 also reveals the presence of needle-like $\delta\left(\mathrm{Ni}_{3} \mathrm{Nb}\right)$ phase and blocky precipitates that are presumed to be carbides that are typically noted in EBM-built Alloy 718. It is also apparent that the distribution of $\delta$-precipitates varies between the three specimens 
and, as discussed later; this variation is attributable to the location of the specimens within the build architecture shown in Fig. 1. These phases are more clearly discernible in the high magnification micrographs shown in Fig. 5. The major phases identified using the EDS analysis are the $\gamma(\mathrm{Ni}, \mathrm{Cr}, \mathrm{Fe})$ matrix phase, the acicular $\delta\left(\mathrm{Ni}_{3} \mathrm{Nb}\right)$ phase and the blocky primary carbides (MC) [21], which are mostly comprised of $\mathrm{Nb}$ and $\mathrm{C}$, with Ti also being occasionally present in very small amounts [22]. These common phases with the representative EDS results are depicted more clearly in Fig. 6 for the as-built \#1 specimen. Both chemical composition and the phase morphology are consistent with the previously published literature [23]. The $\delta$ and MC phases are both found to be present in the inter- as well as intra-granular regions, as shown in Fig. 4 andFig. 5. Parallel arrays of $\delta$ precipitates with distinct orientations were observed in the grain interior which could be due to the reported orientation dependence of $\delta$ needles and the $\gamma$ matrix [24].
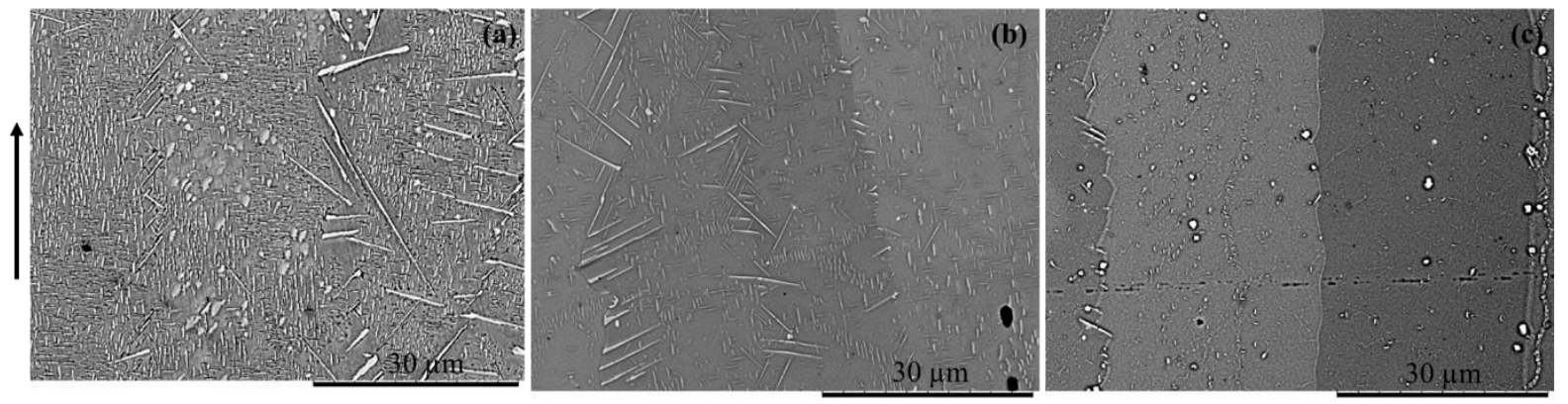

Fig. 4 Low magnification SEM micrographs of specimens (a) \#1 (Z=5 mm), (b) \#2 (Z=61 mm) and (c) \#3 (Z= $117 \mathrm{~mm}$ ) in the as-built condition. The arrow indicates the build direction.

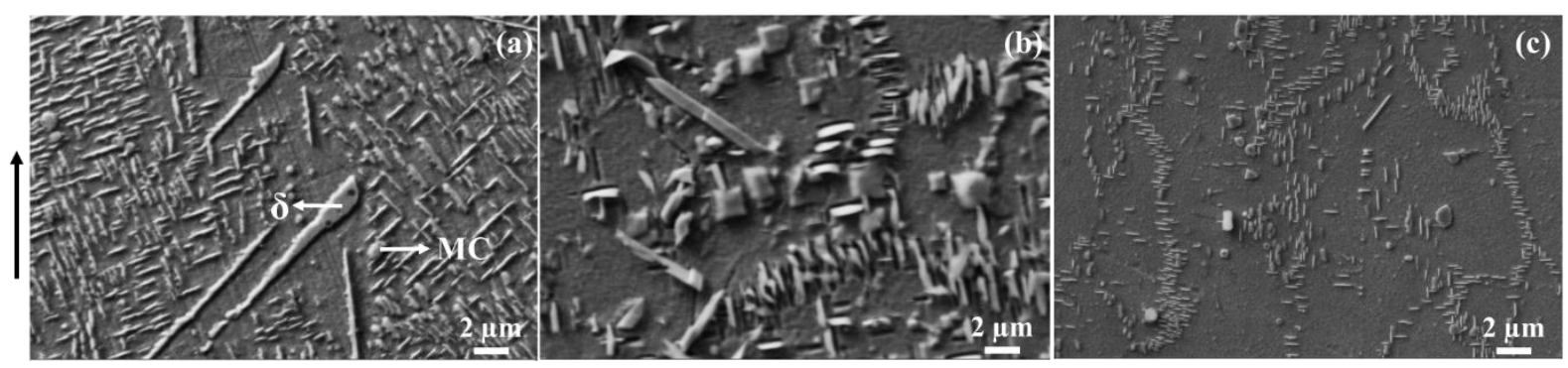

Fig. 5 High magnification SEM micrographs of specimens a) \#1 $(Z=5 \mathrm{~mm}),(b) \# 2(Z=61 \mathrm{~mm})$ and $(\mathrm{c}) \# 3(\mathrm{Z}=$ $117 \mathrm{~mm}$ ) in the as-built condition. The arrow indicates the build direction. 


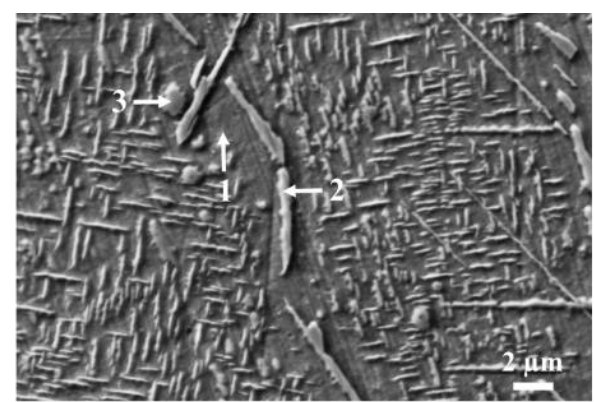

\begin{tabular}{cccccccc}
\hline Spot & Phase designation & $\mathbf{C}$ & $\mathbf{N b}$ & $\mathbf{T i}$ & $\mathbf{N i}$ & $\mathbf{C r}$ & $\mathbf{F e}$ \\
\hline 1 & $\gamma$ & 8.02 & 1.49 & 0.72 & 47.12 & 20.73 & 19.55 \\
2 & $\delta$ & 8.19 & 11.40 & 2.36 & 61.70 & 4.07 & 7.06 \\
3 & $\mathrm{MC}$ & 51.10 & 34.23 & 6.57 & 4.63 & - & - \\
\hline
\end{tabular}

Fig. 6 Representative EDS spot analysis of phases and precipitates commonly observed in the as-built EBM 718 specimens, using specimen $\# 1(Z=5 \mathrm{~mm})$ as an illustrative example.

It can be seen from Fig. 5 that the specimen built closer to the base plate at $Z=5 \mathrm{~mm}$ (specimen \#1) has a higher amount of $\delta$ phase compared to the specimen built near the top of build at $Z=117 \mathrm{~mm}$ (specimen \#3), furthest away from the base plate. In order to understand this incremental variation of $\delta$ phase arising due to the difference in location of the specimens within the build architecture, the thermal history of the specimens was analysed. During the entire EBM build a thermocouple placed in contact with the centre of the underside of the stainless steel base plate, was used to monitor the temperature. Although no real-time measurement of the thermal history of the different build specimens was available, this recorded temperature is frequently used as a rough approximation of the temperature of the bulk-solidified material in the build volume [4], [25]. The temperature profile of the present build, shown in Fig. 7, clearly reveals that specimen \#1 was held at elevated temperature for longer duration than specimen \#2 and \#3. It has been previously reported that the metastable $\gamma$ " transforms into the stable $\delta$ phase when the alloy is exposed for prolonged aging times or to temperatures higher than $650{ }^{\circ} \mathrm{C}$ [8], [23]. In the present study, both these conditions are fulfilled for specimen \#1, which was subjected to temperatures ranging from $\sim 1000^{\circ} \mathrm{C}$ to $\sim 700{ }^{\circ} \mathrm{C}$ for $78 \mathrm{~h}$ as shown in Fig. 7. These thermal conditions likely resulted in significantly greater $\delta$ phase content compared to specimens \#2 and \#3, which were subjected to much shorter durations (46 h and $25 \mathrm{~h}$, respectively) to temperatures ranging from $\sim 850{ }^{\circ} \mathrm{C}$ to $700{ }^{\circ} \mathrm{C}$. 


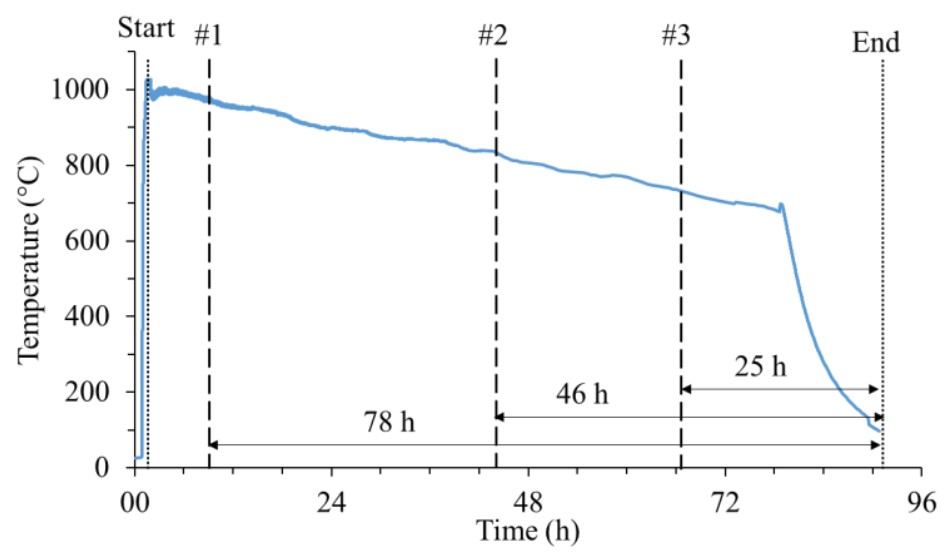

Fig. 7 Temperature profile during the entire EBM build process used to generate the specimens investigated. The start and end of build, as well as the time at which building of each specimen was completed, are indicated.

\subsection{Role of post-treatments}

The influence of both post-treatments, namely HIP and HIP+HT, on all the above microstructural features noted in as-built specimens was further investigated. As summarized in Table 3, the HIP and HIP+HT treatments were found to lead to significant reduction in defect concentration (including both kinds of porosities and lack-of-fusion as previously shown in Fig. 3) from $0.17 \%$ in as-built condition (Fig. 8(a)) to $0.03 \%$ after HIP alone (Fig. 8(b)) and to $0.02 \%$ after HIP+HT (Fig. 8(c)). Table 3 shows the results of defect concentration for specimen \#3, however similar observations were made for specimens \#1 and \#2.

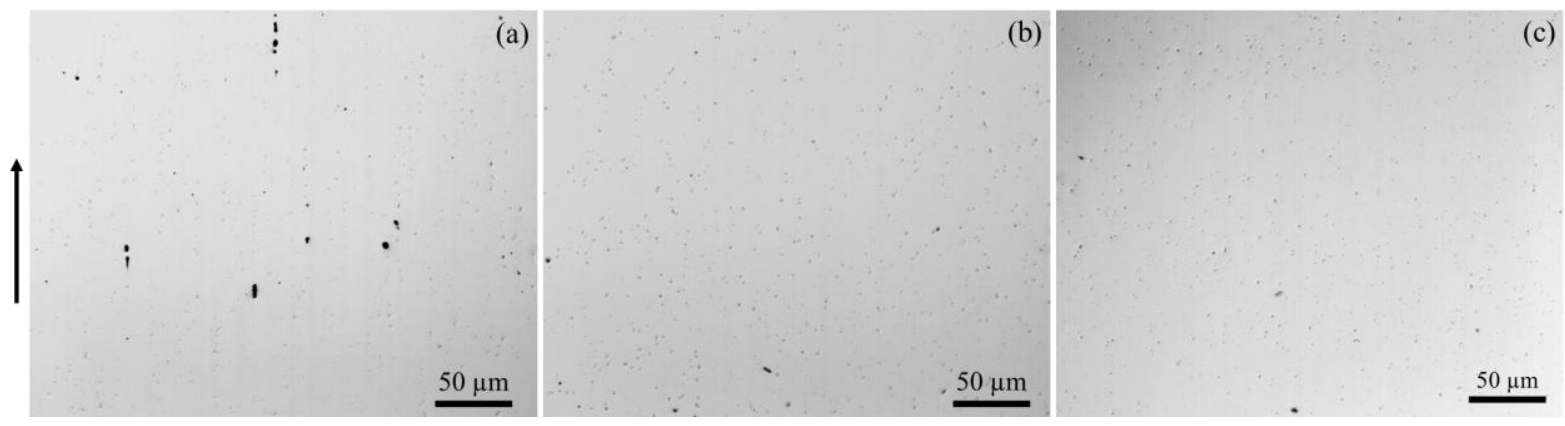

Fig. 8 Typical OM micrographs showing the porosity defect distribution in the (a) as-built, (b) HIP and (c) HIP+HT conditions. The arrow indicates the build direction

Both the post-treatments (HIP and HIP+HT) led to nearly complete dissolution of the $\delta$ phase, irrespective of the widely different size and amount of the $\delta$-needles present in the as-built condition in specimens \#1, \#2 and \#3. As shown in Fig. 9, the SEM micrographs of specimen \#3 reveal the absence of $\delta$-phase and presence of remnant MC carbides after HIP and HIP+HT. It may be concluded that the HIP temperature of $\sim 1200{ }^{\circ} \mathrm{C}$ for $3-4 \mathrm{~h}$ adopted in 
the two cases can lead to complete dissolution of $\delta$ phase, since the temperature was significantly higher than the $\delta$ solvus temperature of $990-1015^{\circ} \mathrm{C}$ [26]. Furthermore, the solution treatment stage during HIP+HT treatment did not result in $\delta$ phase precipitation, which is in accordance with the reported TTT diagram for wrought Alloy 718 [27]. To understand the influence of post-treatment on Alloy 718 built by EBM, specimen \#3 was selected for further investigation.
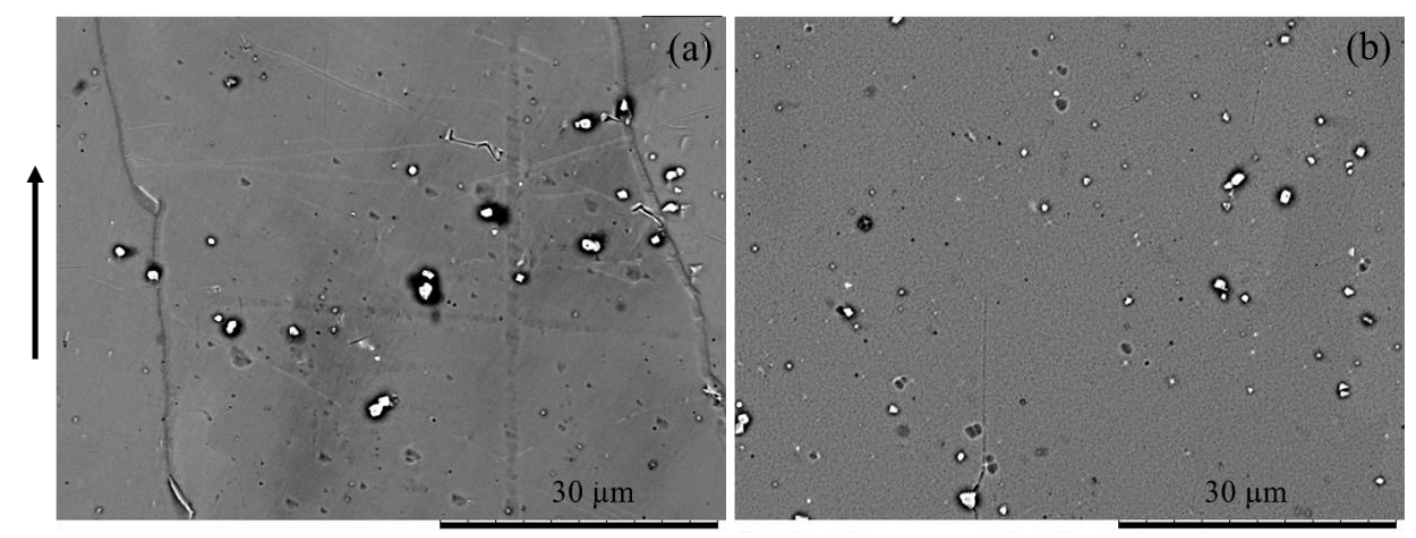

Fig. 9 SEM micrographs of specimen \#3 (Z=117 mm) after (a) HIP and (b) HIP+HT. The arrow indicates the build direction.

Longitudinal grain widths for specimen \#3 in as-built, HIP and HIP+HT conditions are given in Table 3 and reveal extensive grain growth after the HIP treatment despite the retention of the columnar structure. The grain growth may be attributed to the dissolution of $\delta$ phase which has been reported to pin the grain boundaries and be responsible for controlling the grain size in Alloy 718 during heat treatment [1]. Comparing the longitudinal grain widths after HIP and HIP+HT reveals no grain growth during solutionising at $980{ }^{\circ} \mathrm{C} / 1 \mathrm{~h} / \mathrm{RC}$ and lower temperature two-step aging treatment.

Table 3 Overall defect concentration, longitudinal grain width and blocky carbide phase fraction after fabrication and post-treatments for specimen \#3 $(\mathrm{Z}=117 \mathrm{~mm})$ near the top of the build furthest from the base plate

\begin{tabular}{cccc}
\hline Condition/ Property & Defect (vol.\%) & Grain width & Carbide (vol.\%) \\
\hline As-built & $0.17 \pm 0.07$ & $10.3 \pm 1.8$ & $0.2 \pm 0.04$ \\
HIP & $0.03 \pm 0.03$ & $62.6 \pm 5.8$ & $0.4 \pm 0.09$ \\
HIP+HT & $0.02 \pm 0.01$ & $64.2 \pm 7.1$ & $0.42 \pm 0.1$ \\
\hline
\end{tabular}


For specimen \#3, Table 3 also gives the values of carbide vol.\% in the as-built, HIP and HIP+HT conditions. The higher measured value of carbide content after HIP treatment compared to that in as-built condition, also shown visually in Fig. 4(c) and Fig. 9(a), is indicative of growth of carbide particles during HIP treatment at $1200{ }^{\circ} \mathrm{C}$. Similarly, these measured values of carbide content after HIP and HIP+HT treatments suggests that no further growth of the carbides takes place during the lower temperature solution treatment and aging. However, a detailed study to investigate the growth of carbide particles with time during HIP treatment has not yet been conducted. It is presumed that the extent of carbide growth should be limited because precipitation strengthening through $\gamma$ " also competes for and takes up $\mathrm{Nb}[28]$.

\subsection{Micro-hardness in as-built and post-treated conditions}

The micro-hardness values of all the as-built and post-treated specimens were measured and the results are shown in Fig. 10. For as-built specimens, there is gradual increase in hardness with height within the build, shown in Fig. 1. The hardness of specimen \#1 near the base plate at $Z=5 \mathrm{~mm}$ (HV 324) was lower than the minimum hardness requirement (HV 350) specified as per AMS 5662 [29], the hardness of specimen \#2 at mid build height of $Z=61$ mm (HV 359) and specimen \#3 at top build height of $\mathrm{Z}=117 \mathrm{~mm}$ (HV 416) satisfied/exceeded this requirement. The noted variation in hardness with specimen location in the as-built condition may be attributed to the extent of $\gamma$ ” phase present in each of the three specimens, since $\gamma$ ” is the main strengthening phase in Alloy 718 [8]. It has been previously reported that $\delta\left(\mathrm{Ni}_{3} \mathrm{Nb}\right)$ phase has no significant effect on strength of Alloy 718, but its overprecipitation consumes $\mathrm{Nb}$ which is the strengthening phase forming element resulting in reduction in $\gamma^{\prime \prime}\left(\mathrm{Ni}_{3} \mathrm{Nb}\right)$ phase content of the material [30]. As shown in Figs. 4 and 5 visually, the delta content appears to be greatest for the specimen \#1 $(Z=5 \mathrm{~mm})$ and decreases with build height, while the size and distributions of $\gamma^{\prime \prime}$-precipitates vary with build height for these as-built specimens. These observations are likely linked to the observed differences in micro-hardness.

The post-treatments employed resulted in homogenization of the microstructure of the different specimens \#1, \#2 and \#3, which led to uniform hardness values between the three specimens after HIP and HIP+HT treatment (Fig. 10). However, the hardness values were found to be lower in the HIP only condition ( 235 HV) as compared to the as-built condition (324-416 HV). The hardness levels increased significantly (to $~ 500 \mathrm{HV}$ ) when the posttreatment involved a solution treatment and aging combined with the HIP cycle. To obtain some insight into the observed trends, high magnification SEM examination was used to track the $\gamma^{\prime \prime}$ phase content in as-built and post- 
treated specimens with specimen $\# 3(\mathrm{Z}=117 \mathrm{~mm})$ as a test case. As evident from Fig. 11(a), a large amount of $\gamma^{\prime \prime}$ phase was found in the as-built condition. However, the HIP alone treatment appeared to cause complete dissolution of the $\gamma^{\prime \prime}$ phase (solvus temperature: $900-920{ }^{\circ} \mathrm{C}$ [31]), as evident from the absence of any $\gamma^{\prime \prime}$ precipitates in Fig. 11(b). Previously discussed results (Fig. 9(a)) had also shown that HIP alone treatment led to dissolution of the $\mathrm{Nb}$ rich $\delta$ phase. Thus, it is plausible that a substantial amount of $\mathrm{Nb}$ atoms in solution are available after the HIP cycle to facilitate extensive precipitation of $\gamma$ " during the subsequent two-step aging for the combined HIP+HT cycle, Fig. 11(c).

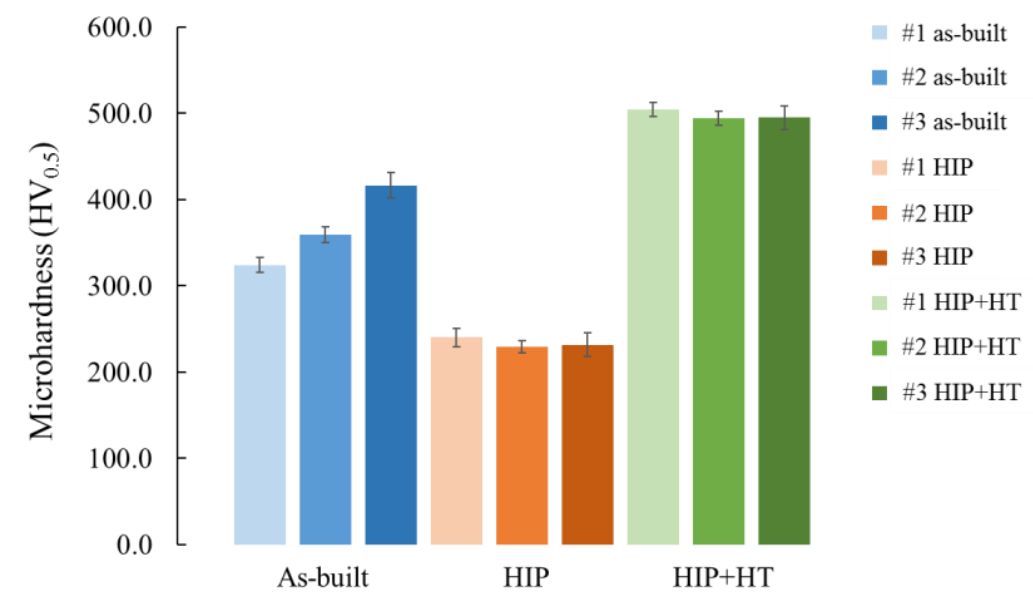

Fig. 10 Micro-hardness of all the specimens in as-built, HIP and HIP+HT conditions.
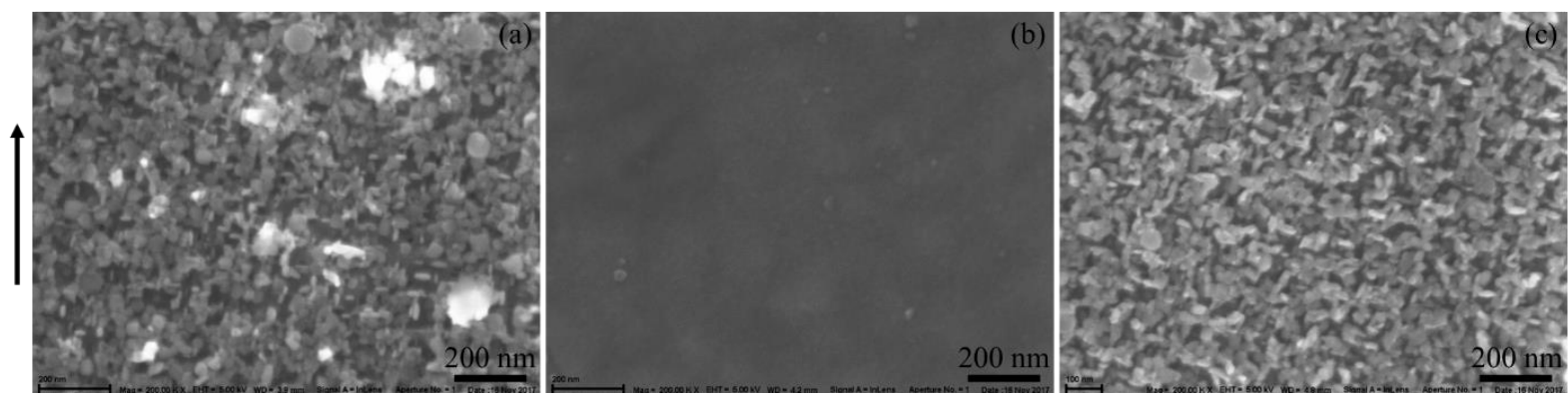

Fig. 11 High magnification SEM micrographs showing $\gamma$ ” in specimen \#3 in (a) as-built and (c) HIP+HT condition, and negligible $\gamma$ " in (b) HIP condition. The arrow indicates the build direction.

XRD analysis was also used to further understand the influence of post-treatments on phase constitution of the asbuilt Alloy 718. The XRD spectra for specimen \#3 in as-built, HIP and HIP+HT condition are shown in Fig. 12, wherein the peaks corresponding to different phases have also been labelled [32], [33]. The $\gamma^{\prime \prime}\left(\mathrm{BCC}, \mathrm{Ni}{ }_{3} \mathrm{Nb}\right) \mathrm{phase}$ diffraction spectra coincide with the $\gamma$ (FCC, matrix) for $111 \gamma\left\|111 \gamma^{\prime \prime}, 200 \gamma\right\| 200 \gamma$ ”, and $220 \gamma \| 220 \gamma^{\prime}$. The XRD 
spectra for the as-built specimen \#3 exhibited prominent (200) texture, which is consistent with the previously published reports on Alloy 718 material manufactured by EBM [34]. The decrease in the intensity of (200) peak could be attributed to the dissolution of $\gamma^{\prime \prime}$, although a definitive conclusion is precluded by the overlapping of the $\gamma$ ” and $\gamma$ peaks. The increase in (111) peak in case of HIP+HT compared to that in as-built and HIP conditions may be attributed to the following possibilities: (a) an increase in the amount of $\gamma$ " after aging step in the HIP $+\mathrm{HT}$ treatment, (b) higher pressure in case of HIP+HT (170 MPa) compared to HIP (120 MPa) treatment. The increase in the intensity of (111) peak with increase in pressure during HIP treatment has been previously reported by Chang et al. [35].

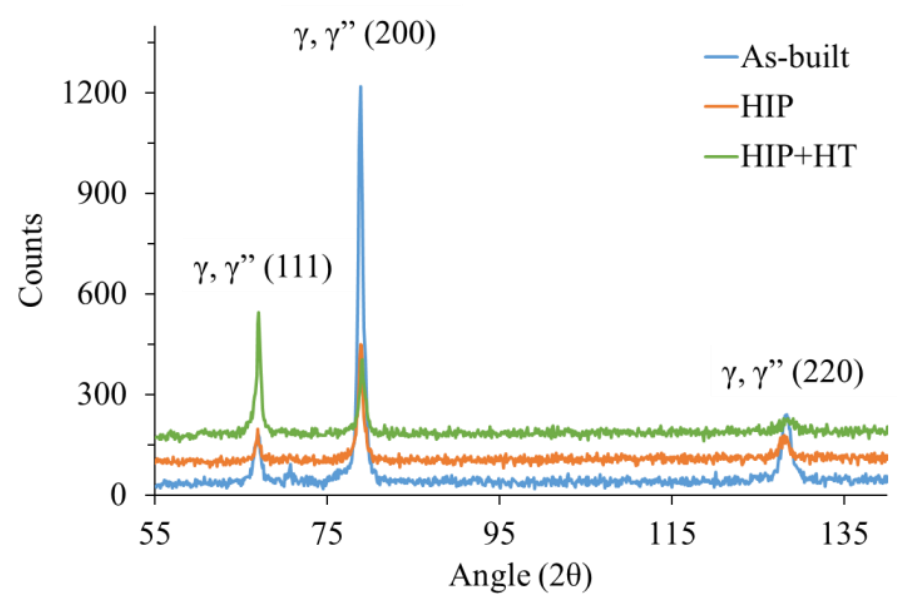

Fig. 12 The X-ray diffraction plots for specimen \#3 in as-built, HIP and HIP+HT condition.

\section{Conclusion}

The effect of HIP alone and HIP with a solutionising and two-step age was investigated for the EBM-built Alloy 718 specimens in the as-built condition for microstructures near the base plate, in the middle of the build and towards the top of the build furthest from the base plate. The major findings of the study are as follows:

1. The as-built specimens contained $\delta-\left(\mathrm{Ni}_{3} \mathrm{Nb}\right)$ needles, blocky $\mathrm{MC}$ carbides and $\gamma$ "'-precipitates. Specimens built closer to the stainless steel base plate experienced longer exposure to high temperature, leading to larger growth of $\delta$ at the detriment of $\gamma$ ”, compared to the specimens built further away from the base plate.

2. Performing a HIP treatment after the build led to significant reduction in defect concentration of the asbuilt specimen and complete dissolution of the $\delta$ phase, irrespective of the $\delta$ phase content in the as-built specimens. 
3. Substantial increase in longitudinal grain width of the native columnar grain structure from about $10 \mu \mathrm{m}$ to about $60 \mu \mathrm{m}$ was observed after both the HIP and HIP+HT treatment, indicating that grain growth occurs during the high temperature HIP cycle.

4. Although the as-built specimens exhibited varying hardness due to the difference in the size and distribution of $\gamma$ " phase resulting from the varied exposure to high temperatures in the powder-bed, after HIP and HIP+HT treatments the specimens exhibited similar hardness, depicting homogenization.

5. The hardness was found to decrease after HIP alone, which is attributed to dissolution of the $\gamma$ " phase. However, the combined HIP, solution treatment and two step aging treatment led to increase in hardness levels beyond those in the as-built condition. This observation was attributed to the re-precipitation of $\gamma$ " during the aging step following HIP.

\section{Acknowledgement}

Dr. Eric Tam and Dr. Yiming Yao, Chalmers University of Technology, are acknowledged for their help with XRD and SEM measurements, respectively. Financial assistance by the KK Foundation (20160281) is gratefully acknowledged.

\section{References}

[1] Fencheng L, Xin L, Menghua S, Weiwei Z, Jing C, Weidong H (2011) Effect of intermediate heat treatment temperature on microstructure and notch sensitivity of laser solid formed Inconel 718 superalloy. J. Wuhan Univ. Technol. Mater. Sci. Ed. 26(5):908-913.

[2] Zhong C, Gasser A, Kittel J, Wissenbach K, Poprawe R (2016) Improvement of material performance of Inconel 718 formed by high deposition-rate laser metal deposition. Mater. Des. 98:128-134

[3] Strößner J, Terock M, Glatzel U (2015) Mechanical and Microstructural Investigation of Nickel-Based Superalloy IN718 Manufactured by Selective Laser Melting (SLM). Adv. Eng. Mater. 17(8):1099-1105

[4] Sames WJ, Unocic KA, Dehoff RR, Lolla T, Babu SS (2014) Thermal effects on microstructural heterogeneity of Inconel 718 materials fabricated by electron beam melting. J. Mater. Res. 29(17):19201930

[5] Gong X, Anderson T, Chou K (2014) Review on powder - based electron beam additive manufacturing technology. Manuf. Rev.1(2)

[6] Sochalski-Kolbus LM, Payzant EA, Cornwell PA, Watkins TR, Babu SS, Dehoff RR, Lorenz M, Ovchinnikova O, Duty C (2015) Comparison of Residual Stresses in Inconel 718 Simple Parts Made by Electron Beam Melting and Direct Laser Metal Sintering. Metall. Mater. Trans. A 46(3):1419-1432

[7] Schirra JJ (1997) Development of a Improved Heat Treatment for Investment Cast Inconel 718 (PWA 649). Paper presented at the Superalloys 718,625,706 and Various Derivatives, Pittsburgh, Pennsylvania, 15-18 June 1997

[8] Anderson M, Thielin AL, Bridier F, Bocher P, Savoie J (2017) $\delta$ Phase precipitation in Inconel 718 and associated mechanical properties. Mater. Sci. Eng. A 679:48-55 
[9] Siereveld P, Radavich JF, Kelly T, Cole G, Widmer R (1988) Effect of HIP parameters on fine grain cast alloy 718. In: Superalloys, SR (ed), DD (ed), GM (ed), SA (ed), CL (ed). The Minerals, Metals \& Materials Society, Champion, PA, p 459-467

[10] Strondl A, Palm M, Gnauk J, Frommeyer G (2011) Microstructure and mechanical properties of nickel based superalloy IN718 produced by rapid prototyping with electron beam melting (EBM). Mater. Sci. Technol. 27(5):876-883

[11] Kirka MM, Medina F, Dehoff R, Okello A (2017) Mechanical behavior of post-processed Inconel 718 manufactured through the electron beam melting process. Mater. Sci. Eng. A 680:338-346

[12] Deng D, Moverare J, Peng RL, Söderberg H (2017) Microstructure and anisotropic mechanical properties of EBM manufactured Inconel 718 and effects of post heat treatments. Mater. Sci. Eng. A 693:151-163

[13] Deng D, Saarimä J, Sö H (2016) Microstructural characterization of as-manufactured and heat treated electron beam melted inconel 718. Paper presented at the Materials Science and Technology, Salt Lake City, UT 24-26 October 2016

[14] Pröbstle M, Neumeier S, Hopfenmüller J, Freunda LP, Niendorf T, Schwarze D, Göken, M (2016) Superior creep strength of a nickel-based superalloy produced by selective laser melting. Mater. Sci. Eng. A 674:299-307

[15] Sundararaman M, Mukhopadhyay P, Banerjee S (1994) Precipitation and room temperature deformation behaviour of Inconel 718. Paper presented at the Superalloys 718, 625, 706 and Various Derivatives, Pittsburgh, Pennsylvania, 27-29 June 1994

[16] Kirka MM, Greeley DA, Hawkins C, Dehoff RR (2017) Effect of anisotropy and texture on the low cycle fatigue behavior of Inconel 718 processed via electron beam melting. Int. J. Fatigue 105:235-243

[17] ASTM E1245-03 (2008) Standard Practice for Determining the Inclusion or Second-Phase Constituent Content of Metals by Automatic Image Analysis

[18] ASTM E562-11 (2011) Standard Test Method for Determining Volume Fraction by Systematic Manual Point Count

[19] Helmer HE, Körner C, Singer RF (2014) Additive manufacturing of nickel-based superalloy Inconel 718 by selective electron beam melting: Processing window and microstructure. J. Mater. Res. 29(17):19871996

[20] Sames WJ, Medina F, Peter WH, Babu SS, Dehoff RR (2014) Effect of process control and powder quality on inconel 718 produced using electron beam melting. Paper presented at the 8th International Symposium on Superalloy 718 and Derivatives, Pittsburgh, Pennsylvania, 28 September-1 October 2014

[21] Mitchell A, Schmalz AJ, Schvezov C, Cockcroft SL (1994) The Precipitation of Primary Carbides in Alloy 718. Paper presented at the Superalloys 718, 625, 706 and Various Derivatives, Pittsburgh, Pennsylvania, 27-29 June 1994

[22] Mitchell A (2010) Primary carbides in Alloy 718. Paper presented at the 7th International Symposium on Superalloy 718 and Derivatives, Pittsburgh, Pennsylvania, 10-13 October 2010

[23] Belan J (2017) The influence of applied heat-treatment on in 718 fatigue life at three point flexural bending. Metallurgy 56(1-2):167-170

[24] Yun Z, Xuebing H, Yong W, Weicheng Y, Zhuangqi H (1997) DELTA PHASE AND DEFORMATION FRACTURE BEHAVIOUR OF INCONEL 718 ALLOY. Paper presented at the Superalloys 718,625,706 and Various Derivatives, Pittsburgh, Pennsylvania, 15-18 June 1997

[25] Jamshidinia M, Kong F, Kovacevic R (2013) Numerical Modeling of Heat Distribution in the Electron Beam Melting® of Ti-6Al-4V. J. Manuf. Sci. Eng. 135(6):061010

[26] Frank RB, Roberts CG, Zhang J (2010) Effect of nickel content on delta solvus temperature and mechanical properties of alloy 718. Paper presented at the 7th International Symposium on Superalloy 718 and Derivatives, Pittsburgh, Pennsylvania, 10-13 October 2010

[27] Oradei-Basile A, Radavich JF (1991) A Current T-T-T Diagram for Wrought Alloy 718. Paper presented at the Superalloy 718, 625 and Various Derivatives, Pittsburgh, Pennsylvania, 23-26 June 1991 
[28] Kuo CM, Yang YT, Bor HY, Wei CN, Tai CC (2009) Aging effects on the microstructure and creep behavior of Inconel 718 superalloy. Mater. Sci. Eng. A 510-511:289-294

[29] SAE Aerospace (2009) Aerospace Material Specification: AMS5662

[30] Cai D, Zhang W, Nie P, Liu W,Yao M (2007) Dissolution kinetics of $\delta$ phase and its influence on the notch sensitivity of Inconel 718. Mater. Charact. 58(3):220-225

[31] Niang A, Viguier B, Lacaze J (2010) Some features of anisothermal solid-state transformations in alloy 718. Mater. Charact. 61:525-534

[32] Raghavan S, Zhang B, Wang P, Sun C-N, Nai MLS, Li T, Wei J (2016) Effect of different heat treatments on the microstructure and mechanical properties in selective laser melted INCONEL 718 alloy. Mater. Manuf. Process. 0(0):1-8

[33] Amato KN, Gaytan SM, Murr LE, Martinez E, Shindo PW, Hernandez J, Collins S, Medina F (2012) Microstructures and mechanical behavior of Inconel 718 fabricated by selective laser melting. Acta Mater. 60(5):2229-2239

[34] Strondl A, Fischer R, Frommeyer G, Schneider A (2008) Investigations of MX and $\gamma^{\prime} / \gamma^{\prime \prime}$ precipitates in the nickel-based superalloy 718 produced by electron beam melting. Mater. Sci. Eng. A 480(1-2):138147

[35] Chang SH, Lee SC, Tang TP, Ho HH (2006) Evaluation of HIP pressure on Inconel 718 superalloy. Int. J. Cast Met. Res. 19(3):181-187 